\title{
Patterns of Attendance of Children Under 12 Years at School Dental Service in Western Australia
}

\author{
S.P.L. Lam ${ }^{1}$, H. Baros ${ }^{1}$, M.J. O’ Grady ${ }^{1}$, G.E. Kendall ${ }^{2}$, L.B. Messer ${ }^{3}$ and L.M. Slack-Smith ${ }^{1 *}$ \\ ${ }^{I}$ School of Dentistry, The University of Western Australia, Perth, Western Australia \\ ${ }^{2}$ School of Nursing and Midwifery Curtin University and Telethon Institute for Child Health Research Centre for Child \\ Health Research, University of Western Australia, Perth, Western Australia \\ ${ }^{3}$ Melbourne Dental School Faculty of Medicine Dentistry and Health Sciences, The University of Melbourne, \\ Melbourne, Victoria, Australia
}

\begin{abstract}
The aim of this study was to investigate the patterns of attendance at School Dental Service (SDS) and reasons for attendance (treatment or prevention) for children in the Perth Metropolitan Area, in particular investigating the first year of SDS attendance and attendance until the year the child turned 12. The first 150 SDS records located for children from the Western Australian Pregnancy Cohort (Raine) Study were used for this study. Patterns of attendance of children at SDS were described, as were associated factors (enrolment, age and nature of first visit, general nature of visits and number of visits) until the end of the year that the child turned 12.

The age of the child at the first SDS visit ranged from 4 years 3 months to 14 years 11 months, with a median of 5 years 1 month. First visits were primarily for an examination (98\%). Children had a median of 13 visits until 12 years of age, with $10 \%$ having less than five visits and $4 \%$ having more than 25 visits.
\end{abstract}

These data provide useful information regarding attendance at the SDS in Western Australia which could provide a basis for oral health promotion programs.

Keywords: Children, dental services, oral health, prevention.

\section{INTRODUCTION}

This was a study undertaken to describe the first year of attendance at the School Dental Service (SDS) and the number of visits until the year the child turned 12. The Western Australian Pregnancy (Raine) Cohort Study was used as the sampling frame for this study to provide baseline information on such attendance [1]. The focus with investigating these data was on attendance and whether the visit was focused on prevention or treatment.

In 2008, dental services accounted for approximately $10 \%$ of total health system expenditure (over $\$ 5.3$ billion) in Australia [2]. Dental caries (decay), in particular, is a significant chronic disease with extensive morbidity across age groups and consequent social and financial costs [3]. While dental caries is one of the most common chronic diseases of childhood [3,4], it is largely a preventable and reversible infectious disease process [5].

*Address correspondence to this author at the School of Dentistry (M512) The University of Western Australia 35 Stirling Highway CRAWLEY Western Australia 6009; Tel: +618 9346 7636; Fax: +618 9346 7666;

E-mail: linda.slack-smith@uwa.edu.au
The SDS provides a total population approach to prevention and early treatment for most Australian school children [6]. The type of care the SDS typically provide includes examinations, fillings, extractions, dental cleaning, radiographs and oral hygiene/tooth brushing instruction [7,8]. The Australian states and territories provide separate SDS, with some variations in each service, including eligibility criteria for applicants, priority age groups, the nature of services provided and data collected [9]. Many state SDS collect records by dental therapists and dentists, storing hard copy dental records at locations near where the child attends school. These records normally include the age and gender of children, their caries experience for both primary and secondary teeth, history of dental examinations and the prevalence and frequency of fissure sealants [8].

The SDS in Western Australia (WA) provides free basic dental care for all school children [7] and is staffed primarily by dental therapists who are supervised by dentists $[7,10]$. In WA, all school children from Preschool to Year 11 (and also Kindergarten children on parent request), are eligible for enrolment in the SDS [11]. [(http://www.dental.wa.gov.au/school/eligibility.php)] We know only $40 \%$ of children under five years in Australia attend a dental professional [12] 


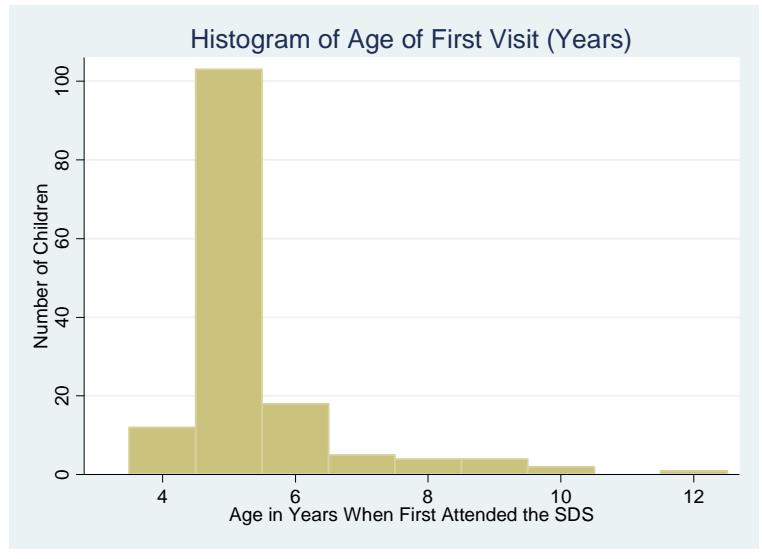

* Graph limited to age 12 years

Fig. (1). Histogram of Age (in years) of the First Visit to School Dental Service*.

and the majority of children attend SDS for their first visit $\{$ Slack-Smith, personal communication $\}$.

The reason for a dental visit can be broadly categorized into preventive or treatment of a problem. From results of parent interviews in a 2002 National Dental Telephone Interview Survey, approximately $17 \%$ of 5-17 year old children visited the dentist to attend to a problem rather than just a check-up [13]. Children from South Australia had the lowest proportion of problem-oriented visits $(8 \%)$, while the Australian Capital Territory had the highest (23\%). In WA the proportion of problem-oriented visits was $15 \%$ [14].

Clinicians choose an appropriate recall interval for each patient. [7] In 1995, it was reported by Riordan that the average recall interval in WA was over 12 months, which reduced treatment costs for the SDS as the dental professional could see more children during that time period. Mean recall intervals increased in successive years since the mid-1980s; it was postulated at that time that the recall intervals for WA children could be increased further without measurable adverse health effects. [15] Western Australian children aged 5-6 have an average dmft 1.60 (compared to Australian overall 1.90) in 2003-4 (decayed) component of 1.05 (compared to Australian overall 1.29) and dmft 1.65 (sd. 4.06) compared to Australia 2.21 (sd 3.24) in 2006 [16, 17].

The Western Australian Pregnancy Cohort (Raine) Study is a prospective pregnancy cohort where almost 3,000 women were enrolled at or before the 18th week of gestation from clinics at King Edward Memorial Hospital (KEMH) from May 1989 to November 1991 [18]. The overall aim of the Western Australian Pregnancy (Raine) Cohort Study is to determine how events during pregnancy, around birth, and in early childhood influence subsequent health and development. As KEMH is the only specialist obstetric care centre in the state, the initial sample was at moderate obstetric risk. The cohort has since been noted as reasonably representative of the general population [1].

This study investigated the first 150 SDS records retrieved for a sample of Metropolitan children from the Western Australian Pregnancy (Raine) Cohort Study. The overall aim of this study was to describe initial and primary school attendance at SDS and, in particular, to investigate (i) age of child at first visit to SDS and (ii) nature of visits to SDS in the first year of SDS attendance. In addition children were followed until the year they turned 12 years of age to determine: (iii) number of visits until child reached 12 years and; (iv) reason for visits until child reached 12 years.

\section{MATERIALS AND METHODOLOGY}

The first 150 SDS records retrieved for children as a convenience sample from a random list of 300 children from the Western Australian Pregnancy (Raine) Cohort Study were investigated (the random list would include children who do not attend SDS). The data from SDS records were entered into a Microsoft Access 2007 database for data management and checking. Children were included when they lived in the Perth Metropolitan Area and were still considered active participants of the Raine Study at age 13 years Visits to SDS until the end of the year the child turned 12 were investigated in this study. The SDS reporting and treatment centres were categorized based on postcodes for health regions (fromhttp://www.health.wa.gov.au/servicees/detail.cfm?Unit_ID=2283).

Analyses were conducted to describe the patterns and trends of the SDS visits of the children based on the aims and objectives of this study. Missing data were excluded from the analysis. These descriptive analyses were conducted using Stata Version 10 (StataCorp. 2007. Stata Statistical Software: Release 10. College Station, TX: StataCorp LP).

Such data required careful interpretation. For example, treatment would rarely be undertaken in the first visit. When a new patient required a restoration or presented with moderate symptoms, treatment would often be postponed until the next appointment, hence we have looked at reasons for the visit in the first year rather than just the first visit.

This project is part of a research project which has received appropriate approval from the Human Research Ethics Committee of the University of Western Australia, and the Confidentiality of Health Information Committee and Dental Health Services at the Department of Health, Western Australia.

\section{RESULTS}

The first 150 SDS records retrieved for the Raine Study children were sampled. A description of the sample is provided in Table 1. The SDS treatment centres collected information on the SDS records, with these records then forwarded to SDS reporting centres.

\section{AGE OF CHILD AT FIRST VISIT TO SCHOOL DEN- TAL SERVICE}

The age at which the children first visited SDS ranged from 4 years 3 months to 14 years 11 months, with a median of 5 years 1 month. The number of visits within the first year is presented in Table $\mathbf{2}$. Only two children commenced visits after age 12 and one of these was within the year they turned 12. The analyses in this paper for Tables $\mathbf{3}$ and $\mathbf{4}$ will only refer to the attendance until the end of the year the child turned 12. Fig. (1) demonstrates the distribution of the age of the child in years when they first attended SDS. 
Table 1. Description of the Sample of Children in The Study

\begin{tabular}{|c|c|c|c|c|}
\hline Variable & Description & Level & Number $n=150$ & Percentage (\%) \\
\hline \multicolumn{5}{|l|}{ Child Characteristics } \\
\hline Gender & Gender of the child & $\begin{array}{l}\text { Male } \\
\text { Female }\end{array}$ & $\begin{array}{l}80 \\
70\end{array}$ & $\begin{array}{l}53 \\
47\end{array}$ \\
\hline Region where child lives\#! & Health regions (based on postcodes) & $\begin{array}{c}\text { North Metro } \\
\text { South Metro } \\
\text { East Metro }\end{array}$ & $\begin{array}{l}34 \\
46 \\
68\end{array}$ & $\begin{array}{l}23 \\
31 \\
45\end{array}$ \\
\hline Year of birth & Year the child was born & $\begin{array}{l}1989 \\
1990 \\
1991 \\
1992\end{array}$ & $\begin{array}{c}8 \\
59 \\
61 \\
22\end{array}$ & $\begin{array}{c}5 \\
39 \\
41 \\
15\end{array}$ \\
\hline
\end{tabular}

\section{SDS Attendance Characteristics for Child}

\begin{tabular}{|c|c|c|c|c|}
\hline Age First Visit\# & $\begin{array}{l}\text { Age of the child's first visit } \\
\text { (years, inclusive) }\end{array}$ & $\begin{array}{c}\text { under } 4 \\
4 \\
5 \\
6 \\
7 \\
8-10 \\
>10\end{array}$ & $\begin{array}{c}0 \\
61 \\
70 \\
5 \\
6 \\
5 \\
2\end{array}$ & $\begin{array}{c}0 \\
41 \\
47 \\
3 \\
4 \\
3 \\
1\end{array}$ \\
\hline SDS Reporting Centre* & Health regions (based on postcodes) & $\begin{array}{c}\text { North Metro } \\
\text { South Metro } \\
\text { East Metro }\end{array}$ & $\begin{array}{l}47 \\
38 \\
65\end{array}$ & $\begin{array}{l}31 \\
25 \\
43\end{array}$ \\
\hline Total Number & & & 150 & $\sim 100$ \\
\hline
\end{tabular}

\section{NATURE OF FIRST VISIT AND VISITS IN THE FIRST YEAR OF SDS ATTENDANCE}

Of these 150 records, one was not included in analysis of visit reason because the child was over 12 years of age at the first visit; 146 (98\%) recorded an examination at the first visit. Few restorations were conducted at the first visit $(n=3$, $0.02 \%$ ). Generally, fluoride applications, extractions (due to caries), orthodontic referrals and radiographs were not conducted during the first visit. Overall, $65 \%$ of children had one or two visits in the first year. We noted $89 \%$ of children had an examination at their second visit within the first year.

Table 2. Number of Visits in the First Year of School Dental Service Attendance

\begin{tabular}{|c|c|c|}
\hline $\begin{array}{c}\text { Number of } \\
\text { Visits }\end{array}$ & $\begin{array}{c}\text { Number of } \\
\text { Children }\end{array}$ & $\begin{array}{c}\text { Proportion of Children } \\
(\boldsymbol{\%})\end{array}$ \\
\hline \hline 1 & 37 & 25 \\
\hline 2 & 60 & 40 \\
\hline 3 & 20 & 13 \\
\hline 4 & 18 & 12 \\
\hline 5 & 9 & 6 \\
\hline $6-11$ & 6 & 4 \\
\hline Total & 150 & 100 \\
\hline
\end{tabular}

Table 3. Total Number of Visits Until the End of the Year Child Turned 12

\begin{tabular}{|c|c|c|}
\hline Number of Visits & $\begin{array}{c}\text { Number of } \\
\text { Children }\end{array}$ & $\begin{array}{c}\text { Proportion of Chil- } \\
\text { dren (\%) }\end{array}$ \\
\hline \hline $1-5$ & 16 & 11 \\
\hline $6-10$ & 33 & 22 \\
\hline $11-15$ & 60 & 40 \\
\hline $16-20$ & 23 & 15 \\
\hline $21-25$ & 11 & 7 \\
\hline $26-30$ & 6 & 4 \\
\hline Total & 149 & 100 \\
\hline
\end{tabular}

NUMBER OF VISITS UNTIL THE END OF THE YEAR THE CHILD TURNED 12

The number of visits the child had attended until reaching 12 years of age is summarized in Table 3. Most children in the sample had between 11 and 15 visits in this time (40\%), while only a few (4\%) had more than 25 visits.

\section{NATURE OF SCHOOL DENTAL SERVICE VISITS UNTIL THE CHILD TURNED 12}

This study was not intended to investigate reasons for dental visits in detail. However, details of important recorded procedures are given in Table 4. Episodes of attendance in- 
Table 4. Number and Proportion of Children that Have Recorded a Specific Procedure to End of Year Child Turned 12

\begin{tabular}{|c|c|c|}
\hline \multirow{2}{*}{ Procedure } & \multicolumn{2}{|c|}{ Frequency of Procedure } \\
\cline { 2 - 3 } & \multicolumn{2}{|c|}{ Undergone } \\
\cline { 2 - 3 } & & \% of Children \\
\hline \hline Examination & 149 & 100 \\
\hline Restoration & 100 & 67 \\
\hline Radiographs & 99 & 66 \\
\hline Fissure Seal & 64 & 43 \\
\hline Orthodontic Referral & 59 & 39 \\
\hline Prophylaxis & 49 & 33 \\
\hline Fluoride treatment & 64 & 43 \\
\hline Scale treatment & 60 & 40 \\
\hline Extraction & 57 & 38 \\
\hline Trauma review & 8 & 5 \\
\hline Orthodontics & 3 & 2 \\
\hline
\end{tabular}

* Some procedures such as oral hygiene instruction were incompletely recorded

cluded 1,960 visits for examination, 551 for restoration and 118 for radiographs (where there may have been multiple reasons for visits).

Visits comprised mainly of examinations $(73 \%$ of total visits recorded). Every child in the sample had undergone an examination.

\section{DISCUSSION}

In this study we have described the pattern of SDS visits for a sample of children in the Perth Metropolitan Area with a focus on visits in the first year and those up to the age of 12 years. The SDS provides an important service to school age children and data on attendance and service use is limited. However, this initial study adds to the understanding of SDS attendance, given the dearth of information in this area and provides a basis for future epidemiological studies.

As indicated by the recent literature, enrolment in the SDS is often the first contact with a dental service for Australian children [12]. However, only $38 \%$ of Western Australian children were reported in the previous study to have visited a dental professional by the age of four years [12]. Previous research has indicated that Western Australia had the lowest proportion of preschool children having ever visited the dentist while South Australia had the highest proportion [20]. It is important to investigate the reason for such a variation as early diagnosis and prevention would improve child dental management and reduce dental morbidity and costs.

International research and paediatric dental groups support early contact with a dental service [21-23], indicating significant preventive value of a first dental visit at the age of $2.5-3$ years old [21]. This raises important issues. If the majority of WA children have their first dental visit to SDS after five years of age, this indicates a need to either extend the SDS to earlier years or actively promote/encourage earlier attendance. The latter has been implemented in Western Australia through the "Lift the Lip" campaign. Lift the Lip is a program that targets children 0-4years old, encouraging parents or non-dental child health professionals to literally lift the child's lip and to refer to a dental professional if necessary. This program was introduced in Western Australia in October 2010, following in the footsteps of South Australia and New South Wales. As yet, there are no statistics available regarding the success of this program. \{Personal communication, Denise Brockman\}.

In the Nordic countries, a 2007 study of 3,000 children aged 2-17 years showed that there was a significant decline in public dental service attendance, despite the widely available and free/subsidised dental health services [19].

Apart from having their dental contact at the SDS, a minority of children visit a private dental clinic prior to attending the SDS. In the present study, any previous treatment by a private dental clinic may have been indicated by the child presenting with existing restorations at the first visit or may not have been known. This was a limitation of the current study.

The nature of the first visit was considered but even if the child required treatment or fluoride treatment, this was unlikely to be conducted in the first visit. The dental professional would have been likely carry out a comprehensive examination before any proposed treatment. This is not surprising as it has been reported that majority of preschool children ( 3 and 4 years old) have visited a dental professional for an examination instead of presenting with a problem [12].

The recall interval is often based on the need for treatment as the child would return to the SDS for more visits in a shorter frame of time if he/she required a specific procedure, especially if the dental need was urgent. Past studies ${ }^{7}$ have suggested that the recall intervals for WA children could be increased further without measurable adverse health effects, however further data would assist such decisions.

This study was not intended to investigate reasons for dental visits in detail. However, it was determined that the majority of visits were for an examination or check-up. This is supported by a general observation (as has been mentioned) that the majority of children visited a dental professional for an examination/check-up as opposed to a dental problem [12]. Available evidence from SDS indicates a low burden of caries in these children but this may also be an underestimate given many children do not have radiographs [16]. Anecdotal evidence (from a number of sources) indicates that general practitioner dentists often prefer not to see children under five years of age and this may have been exacerbated by the fact that many children attend the SDS and general practitioner dentists do not gain experience with young children.

This was a preliminary study which provided information on what data is available in School Dental Service records. There are limitations on using such administrative data for research when it was not collected for this purpose. 
However, this initial study was important to gain an understanding of SDS attendance, to address a gap in the literature, and it provides a basis for future epidemiological studies. This study provides unique Western Australian information on school dental service use in pre-primary and primary school children. This will assist in planning appropriate dental care and oral health promotion and provide useful information for future research.

\section{CONCLUSION}

This study provides a description of attendance at SDS for the first year and until age 12 years. This provides useful information on the patterns of SDS visits of young children and further investigations of their characteristics will provide information that can assist service provision and oral health promotion planning.

\section{ACKNOWLEDGEMENTS}

The authors would like to acknowledge The Raine Study participants and their families, School Dental Services, particularly Dr Peter Jarman and Ms Tammy Richards and previous advice by Dr David Neesham; the Raine Study team for cohort co-ordination in particular Jenny Mountain and Melinda Berinson. Dr Anne Read and Julie Pegrum gave advice on the manuscript. Ms Lam was supported by an Australian Dental Research Foundation vacation scholarship and this overall project was supported by an Ada Bartholomew Bequest, Rankine Bequest and the Health Promotion Foundation of Western Australia.

- The NH\&MRC for their long term contribution to funding the Raine Study over the last 20 years.

- The following Institutions are acknowledged for providing funding for Core Management of the Raine Study

- The University of Western Australia (UWA)

- Raine Medical Research Foundation

- UWA Faculty of Medicine, Dentistry and Health Sciences

- The Telethon Institute for Child Health Research

- Women and Infants Research Foundation

\section{CONFLICT OF INTEREST}

None declared.

\section{REFERENCES}

[1] Oddy WH, Kendall GE, Blair E, et al. Breast feeding and cognitive development in childhood: a prospective birth cohort study. Paediatr Perinat Epidemiol 2003;17(1): 81-90.
[2] Australian Institute of Health and Welfare. Australia's health 2008. Canberra AIHW 2008.

[3] Mouradian WE. The face of a child: children's oral health and dental education. J Dent Educ 2001; 65(9): 821-31.

[4] Kohler L, Holst K. Dental health of four-year-old children. Acta Paediatr Scand 1973; 62(3): 269-78.

[5] Edelstein BL. Public and clinical policy considerations in maximizing children's oral health. Pediatr Clin North Am 2000; 47(5): 1177-89, vii.

[6] Al-Yaman F, Bryant M, Sargeant H. Australia's children: their health and wellbeing 2002. AIHW Cat. No. PHE 36. Canberra: AIHW 2002.

[7] Riordan PJ. Secular changes in treatment in a school dental service. Community Dent Health 1995;12(4): 221-5.

[8] Armfield J, Roberts-Thomson K, Slade G, Spencer A. Dental health differences between boys and girls The Child Dental Health Survey, Australia 2000. In: The Child Dental Health Survey, Australia 2000. AIHW cat. no. DEN 131; 2004.

[9] Armfield J, Roberts-Thomson K. Child dental health survey, western Australia 2001. In: Child Dental Health Survey, Western Australia 2001. City: Adelaide: The University of Adelaide 2004.

[10] Riordan PJ, Dalton-Ecker L, Edwards TS. Dental status of 12-yearolds treated in private practice and a school dental service. Community Dent Oral Epidemiol 1993; 21(4):198-202.

[11] Department of health dental health services eligibility information for school age children department of health 2008.

[12] Slack-Smith LM. Dental visits by Australian preschool children. J Paediatr Child Health 2003;39(6): 442-5.

[13] Carter KD, Stewart JF. National dental telephone interview survey 2002. AIHW cat. no. DEN 128 AIHW Dental Statistics and Research Unit 2003.

[14] AIHW access to dental services among Australian children and adults. AIHW, Dental Statistics and Research Unit 2006.

[15] Wang NJ, Riordan PJ. Recall intervals, dental hygienists and quality in child dental care. Community Dent Oral Epidemiol 1995; 23(1): 8-14.

[16] Armfield JM, Spencer AJ, Brennan DS. Dental health of Australia's teenagers and pre-teen children: the Child Dental Health Survey, Australia 2003-04. dental statistics and research series no. 52. Cat. no. DEN 199. Canberra: AIHW.

[17] Ha DH, Roberts-Thomson KF \& Armfield JM 2011. The child dental health surveys Australia, 2005 and 2006. dental statistics and research series no. 54. Cat. no. DEN 213. Canberra: AIHW.

[18] Newnham JP, Evans SF, Michael CA, Stanley FJ, Landau LI. Effects of frequent ultrasound during pregnancy: a randomised controlled trial. Lancet 1993; 342(8876): 887-91.

[19] Virtaner JI, Bentssor LT, Lahelna E, Kohles L, Mustomaa H. Children's use of dental services in the five Nordic countries. J Epidemiol Commun Health 2007; 61(12): 1080-5.

[20] Riordan PJ. Dental caries and fluoride exposure in Western Australia. J Dent Res 1991;70(7):1029-34.

[21] Nainar SM, Straffon LH. Targeting of the year one dental visit for United States children. Int J Paediatr Dent 2003;13(4): 258-63.

[22] British Society of Paediatric Dentistry: a policy document on oral health care in preschool children. Int J Paediatr Dent 2003;13: 27985.

[23] American Academy of Pediatric Dentistry guideline on periodicity of examination, preventive dental services, anticipatory guidance/counseling, and oral treatment for infants, children, and adolescents. Am Acad Paediatr Dent 2007: 23; 11.

Received: February 06, 2012

Revised: March 06, 2012

Accepted: March 07, 2012

(C) Lam et al.; Licensee Bentham Open.

This is an open access article licensed under the terms of the Creative Commons Attribution Non-Commercial License (http://creativecommons.org/licenses/by-nc/3.0/) which permits unrestricted, non-commercial use, distribution and reproduction in any medium, provided the work is properly cited. 